drug will be obvious because the results of leaving patients untreated are so unfavourable. In an earlier report ${ }^{6} 52$ out of Felber's 60 patients said his treatment gave better results than anything they had tried before. On the other hand 15 out of the 28 patients with recurrent disease in the present series reported pain relief as "immediate"-occurring in less than one hour-and it is difficult to see how the drug and the light could have worked so fast. Further, the proflavine or neutral red may have affected the associated secondary bacterial infection. This kind of uncertainty underlines the need for a controlled trial, and, as the authors admit, "this is not a wellcontrolled double-blind study, and the results do nothing more than suggest that a properly conducted study would be worthwhile undertaking". There are disadvantages: any vesicles have to be unroofed, an unpleasant procedure for both operator and patient. A more effective approach may prove to be the use of one of the drugs now known to be effective against herpes in other sites such as idoxuridine or cytosine arabinoside. Whatever the therapy adopted, two assertions can be made. The success of treating herpes infections at other sites has been such that it is unlikely that an effective therapy cannot be devised for genital herpes. On the other hand, it will only be by a controlled trial that the effectiveness, let alone the optimal dosage regimen, will be established.

\footnotetext{
1 Wallis, C., and Melnick, J. L., Photochemistry and Photobiology, 1966, 4, 159 2 Felber, T. D., Smith, E. B., Knox, J. M., Wallis, C., and Melnick, J. L., fournal of the American Medical Association, 1973, 223, 289.

${ }^{3}$ Friedrich, E. G. Jun., Obstetrics and Gynecology, 1973, 41, 74.

- Lefebure, E. B., and McNellis, E. E., fournal of the American Medical Association, 1973, 224, 1039.

${ }^{5}$ Kaufman, R. H., et al., American fournal of Obstetrics and Gynecology, $1973,117,1144$.

Fournal of the American Medical Association 1971, 217, 270.
}

\section{Haemophilus influenzae Infections}

Factors responsible for a decline in the incidence of infection with a particular agent can at times be clearly identifiedimprovements in standards of hygiene and immunization procedures, for example, have controlled typhoid, diphtheria, and polio. On the other hand an increase in the prevalence of an infection is generally more difficult to explain. Infections with Haemophilus influenzae have shown a considerable increase in the past three or four decades. ${ }^{1-3}$ These occur mainly in infancy and early childhood, and there has not been any marked change in the age group at greatest risk. Serious infections do occur in adults, however, as reported by Dr. Susannah Eykyn and her colleagues this week (p. 463).

Several types of encapsulated $H$. influenzae can be identified but only one, type $b$, is commonly responsible for clinical disease in man. The portal of entry is usually the respiratory tract, and the most frequent and serious forms of disease are meningitis and epiglottitis. Otitis media is also common, and less frequently pneumonia, septicaemia, septic arthritis, osteomylitis, and cellulitis can be caused by these organisms. $H$. influenzae has remained remarkably stable in respect of its sensitivity to antibiotics; chloramphenicol, ampicillin, and the tetracyclines are still generally effective, but recently there have been a few reports of organism resistant to ampicillin and chloramphenicol. However, one factor in the seriousness of the infection in some sites is that the early clinical signs can be mild and non-specific, and this often results in a delay in treatment.

$H$. influenzae meningitis is one of the major current concerns.
Recent estimates ${ }^{4}$ from the U.S.A. suggest that there are probably over 10,000 cases a year with 800 deaths, a mortality rate of $0 \cdot 4 / 100,000$ of the total population and 3.8/100,000 in children less than 5 years of age. Also of great concern is the high incidence (nearly 30\%) of residual brain damage in the survivors--and this estimate does not include children with minor degrees of impaired learning ability, who may add another $10 \%$ to the incidence of morbidity.

The overall risk of meningitis in children under 5 is three times that ${ }^{2}$ in $1942-50$. In a study of a population of 360,000 in North Carolina the number of cases has risen ${ }^{5}$ from nine per year in 1966 to 27 per year in 1971, and in children under 5 the attack rate was three times greater in negroes than in white children.

Statistics like these have been a stimulus for research into preventive measures. There have been two approaches in the development of a vaccine. In the first a type-specific antigen has been prepared from the external polyribophosphate capsule, thought to be critical in the pathogenicity of $H$. influenzae. Experiments on animals have shown ${ }^{6}$ that antibody to this antigen in antiserum is protective and anti-type $b$ antibodies in man have also been found ${ }^{7}$ effective. A vaccine composed of the capsular polysaccharide has been subjected ${ }^{8}{ }^{9}$ to trials in human volunteers which showed that antibody responses were both dose- and age-dependent. In children under 12 months of age, however, antibody responses were most unsatisfactory -and this is the age at which the attack rates are highest. A similar phenomenon of age-related antibody response has also been noted ${ }^{1011}$ in natural infection, when little or no antibody was detected in infants. The reasons for these findings are at present unclear and may not necessarily be due to a complete absence of an immune response; indeed using a more sensitive test to measure antibody a response to this type of vaccine has been detected ${ }^{12}$ in 2 - and 3-month-old infants.

The second, indirect approach to immunization is of considerable theoretical interest. It concerns antigens from normal bacterial flora which crossreact because of a component they share with the capsular polysaccharide of $H$. influenzae type b. Several such bacteria have been identified, ${ }^{12}$ including strains of Escherichia coli and other non-pathogenic enteric bacteria. It may be possible ${ }^{15}$ to induce immunity by neonatal feeding with such non-pathogenic enteric bacteria.

The implications for vaccine development are clearly of great importance, but there are many practical problems still to be faced. For example, who is to be immunized and at what age? Answers to such questions are not, however, going to be required until these experimental vaccines have been proved to be of practical value.

1 Michaels, R. H., New England fournal of Medicine, 1971, 285, 666.

2 Smith, E. W. P., and Haynes, R. E., Pediatrics, 1972, 50, 723

Turk, D. C., and May, J. R., Haemophilus Influenzae, p. 27. London, English Universities Press, Ltd., 1967.

- Mortimer, E. A., Pediatrics, 1973, 52, 633.

S Parke, J. C., Schneerson, R., and Robbins, J. B., Fournal of Pediatrics $1972,81,765$.

- Alexander, H. E., Heidelberger, M., and Leidy, G., Yale fournal of Biology and Medicine, 1944, 16, 425.

7 Schneerson, R., Rodrigues, L. P., Parke, J. C., and Robbins, J. B.,

Fournal of Immunology, 1971, 107, 1081.
8 Anderson, P., Peter, G., Johnston, R. B., Wetterlow, L. H., and Smith, D. H., fournal of Clinical Investigation, 1972, 51, 39.

9 Smith, D. H., Peter, G., Ingram, D. L., Harding, A. L., and Anderson, P., Pediatrics, 1973, 52, 637 .
Pethe

10 Peter, G. S., Greenfield, S., Howie, V. M., and Smith, D. H., Pediatric Research, 1971, 5, 401.

11 Norden, C. W., Melish, M., Overall, J. C., and Baum, J., fournal of Pediatrics, 1972, 80, 209.

12 Robbins, J. B., Parke, J. C., Schneerson, R., and Whisant, J., Pediatric Research, 1973, 7, 103.

13 Bradshaw, M. W., Schneerson, R., Parke, J. C., and Robbins, J. B., Lancet, 1971, 1, 1095.

14 Robbins, J. B., Annals of Internal Medicine, 1973, 78, 259.

15 Myerowitz, R. L., Handzel, Z. T., Schneerson, R., and Robbins, J. B., Infection and Immunity, 1973, 7, 137. 